\title{
MENINGKATKAN KETRAMPILAN GURU DALAM MENYUSUN PERANGKAT PEMBELAJARAN MELALUI TRAINING PERANGKAT PEMBELAJARAN
}

\author{
Farida Ariani \\ SD Negeri 46 Rejang Lebong \\ faridaariani@gmail.com
}

\begin{abstract}
ABSTRAK
Tujuan penelitian ini adalah untuk meningkatkan ketrampilan guru dalam menyusun perangkat pembelajaran. Metode penelitian ini adalah penelitian tindakan kelas. Hasil pada siklus I untuk lebih meningkatkan lagi ketrampilan guru dalam menyusun perangkat pembelajaran. Pada siklus I, guru sudah mulai faham dan mampu menyusun perangkat pembelajaran walaupun belum maksimal karena skor yang di dapat dari hasil observasi adalah 106 dengan kriteria skor maksimal 168 Kriteria ketuntasan adalah 75\% dari total skor yaitu 126 yang berarti ketrampilan guru dalam menyusun perangkat pembelajaran cukup baik. Pada siklus II, guru sudah mulai faham dan mampu menyusun perangkat pembelajaran dan sudah maksimal karena skor yang di dapat dari hasil observasi adalah 163 dengan kriteria Skor maksimal 168, Kriteria ketuntasan adalah 75\% dari total skor yaitu 126. Disimpulkan bahwa ketrampilan guru dalam menyusun perangkat pembelajaran sudah sangat baik dalam menyusun silabus, menyusun program tahunan, dan program semester.
\end{abstract}

Kata Kunci: Ketrampilan Guru, Training, Perangkat Pembelajaran

\begin{abstract}
The purpose of this study is to improve teacher skills in developing learning tools. This research method is classroom action research. The results of the first cycle to further improve teacher skills in developing learning tools. In the first cycle, the teacher had begun to understand and was able to arrange the learning kit even though it was not maximal because the scores obtained from observations were 106 with a maximum score criterion 168 The completeness criterion was $75 \%$ of the total score which was 126 which meant the teacher's skills in preparing the learning device were sufficient well. In cycle II, the teacher has begun to understand and is able to compile the learning tools and is maximized because the score obtained from observations is 163 with a maximum score criterion of 168 , the completeness criterion is $75 \%$ of the total score of 126. It was concluded that the teacher's skills in compiling the devices learning has been very good in compiling syllabi, compiling annual programs, and semester programs.
\end{abstract}

Keywords: Teacher Skills, Training, Learning Tools 


\section{PENDAHULUAN}

Pembelajaran merupakan kegiatan yang melibatkan berbagai macam komponen, antara lain: siswa, guru, kurikulum, sarana dan prasarana pendidikan. Perangkat pembelajaran sangat penting bagi guru karena hal ini berkaitan dengan kesiapan guru dalam mengajar di kelas, guru yang memiliki tanggung jawab dan sangat menentukan dalam pencapaian keberhasilan penyelenggaraan pendidikan.

Perangkat pembelajaran di kelas meliputi: silabus, Rencana Pelaksanaan Pembelajaran (RPP), bahan ajar (handout), media powerpoint, dan Lembar Kerja Siswa (LKS) adalah sesuatu yang sangat penting yang harus dibuat serta harus diperhatikan oleh guru, karena perangkat pembelajaran berperan penting untuk kesuksesan proses pembelajaran. Setiap guru pada satuan pendidikan berkewajiban menyusun perangkat pembelajaran secara lengkap dan sistematis agar pembelajaran berlangsung secara interaktif, inspiratif, menyenangkan, menantang, memotivasi siswa untuk berpartisipasi aktif, kreativitas, dan kemandirian sesuai dengan bakat, minat, dan perkembangan fisik serta psikologis siswa

Dianjurkan kepada guru-guru sebelum mengajar agar mempersiapkan perangkat pembelajarn guna memberikan hal yang terbaik bagi peserta didiknya. Jika perangkat pembelajarannya sudah maksimal maka guru pun jadi menyenangkan di kelas, karena sudah di rencanakan matang-matang sebelum guru memasuki kelas. Pada penelitian ini yang di maksud perangkat pembelajaran meliputi Program tahunan (prota), Program Semester (Promes), Silabus serta Rencana Pelaksanaan Pembelajaran (RPP).

Selanjutnya peneliti hendak melaksanakan training perangkat pembelajaran. Kegiatan Training perangkat pembelajaran ini lebih spesifik membahas dan praktik langsung dalam persiapan perangkat pembelajaran melalui pendampingan fasilitator dan narasumber yang berkompeten di bidangnya. Dari latar belakang itulah maka penelitian ini mengambil judul: "Meningkatkan Ketrampilan Guru Dalam Menyusun Perangkat Pembelajaran Melalui Training Perangkat Pembelajaran di SD Negeri 46 Rejang Lebong Tahun 2019 “

Berdasarkan judul dan latar belakang masalah di atas, maka penulis bisa merumuskan masalah sebagai berikut : 1). Bagaimana ketrampilan guru dalam menyusun perangkat pembelajaran di SD Negeri 46 Rejang Lebong sebelum kepala sekolah melaksanakan training perangkat pembelajaran?; 2). Bagaimana ketrampilan guru dalam menyusun perangkat pembelajaran di SD Negeri 46 Rejang Lebong setelah kepala Sekolah melaksanakan training perangkat pembelajaran?; 3). Apakah training perangkat pembelajaran dapat meningkatkan ketrampilan guru dalam menyusun perangkat pembelajaran di SD Negeri 46 Rejang Lebong?. Tujuan yang ingin dicapai adalah untuk mengetahui : 1). Bagaimana ketrampilan guru dalam menyusun perangkat pembelajaran di SD 
Negeri 46 Rejang Lebong sebelum kepala sekolah melaksanakan training perangkat pembelajaran; 2). Bagaimana ketrampilan guru dalam menyusun perangkat pembelajaran di SD Negeri 46 Rejang Lebong setelah kepala sekolah melaksanakan training perangkat pembelajaran; 3). Apakah training perangkat pembelajaran dapat meningkatkan ketrampilan guru dalam menyusun perangkat pembelajaran di SD Negeri 46 Rejang Lebong.

Dalam dunia pendidikan seorang guru harus mempunyai kompetensi yang professional agar kinerjanya bagus dan memuaskan. Jika kinerjanya bagus maka hasil dari didikannya pun bagus dan nantinya akan menentukan nasib bangsa ini karena hasil pendidikan sudah bagus. Oleh karenanya kompetensi guru harus benar-benar di tingkatkan karena menyangkut masa depan bangsa ini.

Basuki (2013) mengatakan bahwa hakikat kompetensi adalah Ketrampilan yang dating dari dalam diri seseorang untuk menjalankan tugasnya sehingga dia mampu melaksanakan pekerjaan dengan maksimal. Sebagai seorang pendidik guru tentu harus mempu mengajar peserta didik agar mampu mandiri, berkarakter yang baik serta dapat bertanggungjawab atas perilaku dan sikapnya sehari-hari. Siswoyo (2013) mengemukakan bahwa kompetensi pedagogik sendiri tidak identik dengan hal-hal teknis belaka, akan tetapi kemampuan guru dalam mengelola pembelajaran kelas (seperti yang dirumuskan dalam PP RI No. 19 Tahun 2005. Kompetensi pedagogik sendiri tidak hanya menfokuskan diri pada perencanaan, pelaksanaan dan penilaian pembelajaran namun juga menguasai ilmu pendidikan.

Menurut Basuki (2013) kompetensi pedagogik adalah ketrampilan dalam mengelola siswa yang meliputi (a) pemahaman wawasan atau landasan kependidikan; (b) pemahaman tentang peserta didik; (c) pengembangan kurikulum atau silabus; (d) perancangan pembelajaran; (e) pelaksanaan pembelajaran yang mendidik dan dialogis; (f) evaluasi hasil belajar; dan (g) pengembangan peserta didik untuk mengaktualisasikan berbagai potensi yang dimilikinya.

Dalam jurnal Pengembangan Kepribadian Guru menjelaskan bahwa kepribadian itu baik itu secara langsung atau tidak langsung pasti berhubungan dengan jiwa individu ; hal ini berkaitan dengan nilai-nilai etis atau kesusilaan dan tujuan hidup. Kepribadian itu manusia itu juga selalu mengandung unsur dinamis, yaitu ada kemajuan-kemajuan atau progress menuju suatu integrasi baru tapi system psikofisis tersebut tidak pernah akan sempurna bisa terintegrasi dengan sempurna. Kepribadian ini mencakup kemampuan adaptasi (menyesuaikan diri) yang karakteristik terhadap lingkungan (Anonim, 2007)

Profesi harus mengandung keahlian, artinya suatu profesi itu mesti ditandai oleh suatu keahlian yang khusus untuk profesi itu. Keahlian itu diperoleh dengan cara mempelajari secara khusus karena profesi bukanlah sebuah warisan Profesi 
dipilih karena panggilan hidup dan dijalani sepenuh waktu. Profesi juga dipilih karena dirasakan sebagai kewajiban sepenuh waktu, maksudnya bukan bersifat part time (Anonim, 2008)

Perangkat adalah alat tempur guru dalam mengajar. Sehingga tanpa alat tempur pasti guru tidak akan maksimal dalam mengajar di kelas. Dengan perangkat pembelajaran ini, guru dapat merancang bagaimana ia akan mengajar di kelas, bagaimana dia akan memperlakukan siswa di kelas. Jadi perangkat pembelajaran adalah serangkaian media atau sarana yang digunakan dan dipersiapkan oleh guru dan siswa dalam proses pembelajaran di kelas. Sedangkan Pengembangan perangkat pembelajaran adalah serangkaian proses atau kegiatan yang dilakukan untuk menghasilkan suatu perangkat pembelajaran berdasarkan teori pengembangan yang telah ada (Anonim, 1999)

Diantara jenis-jenis perangkat pembelajaran yang harus diperhatikan dalam pembelajaran adalah ; 1) Silabus adalah rencana pembelajaran pada suatu dan atau kelompok mata pelajaran atau tema tertentu yang mencakup standar kompetensi, kompetensi dasar, materi pokok atau pembelajaran, kegiatan pembelajaran, indikator, penilaian, alokasi waktu, dan sumber atau bahan atau alat belajar. Silabus merupakan penjabaran standar kompetensi dan kompetensi dasar kedalam materi pokok atau pembelajaran, kegiatan pembelajaran dan indikator pencapaian kompetensi untuk penilaian; 2) Program tahunan adalah rencana penetapan alokasi waktu satu tahun ajaran untuk mencapai tujuan (standar kompetensi dan kompetensi dasar) yang telah ditetapkan. Penetapan alokasi waktu diperlukan agar seluruh kompetensi dasar yang ada dalam kurikulum seluruhnya dapat dicapai oleh siswa; 3). Rencana program semester merupakan penjabaran dari program tahunan. Program tahunan disusun untuk menentukan jumlah jam yang diperlukan untuk mencapai kompetensi dasar, sedangkan program semester diarahkan untuk menjawab minggu keberapa atau kapan pembelajaran untuk mencapai kompetensi dasar itu dilakukan; 4). Rencana pelaksanaan pembelajaran (RPP) adalah rancangan pembelajaran mata pelajaran per unit yang akan ditetapkan guru dalam pembelajaran di kelas. RPP pada hakekatnya merupakan perencanaan untuk memperkirakan atau memproyeksikan apa yang akan dilakukan dalam pembelajaran. Dengan demikian, RPP merupakan upaya untuk memperkirakan tindakan yang akan dilakukan dalam kegiatan pembelajaran. RPP perlu dikembangkan untuk menkoordinasikan komponen pembelajaran, yakni: kompetensi dasar, materi standar, indikator hasil belajar, dan penilaian.

Di lembaga pendidikan formal belum tentu guru mendapatkan ketrampilan yang di perlukan sebagai tenaga pendidikan secara baik, akan tetapi beberapa ketrampilan tertentu , bias di peroleh guru dalam kegiatan pelatihan atau training, karena pelatihan sifatnya khusus jadi guru memperoleh ilmu khusus tentang materi pelatihan. Pelatihan sendiri memang bertujuan untuk memberikan 
ketrampilan khusus bagi tenaga kerja baik itu pendidik maupun staff. Oleh karena itu, diperlukannya Training atau Pelatihan yang dapat memenuhi kebutuhan dan standar dimana karyawan tersebut bekerja serta mencocokkan pribadi karyawan terhadap budaya pada perusahaan yang bersangkutan. Menurut ahli MSDM Gary Dessler, Training atau Pelatihan adalah proses mengajar keterampilan yang dibutuhkan karyawan baru dan lama untuk melakukan pekerjaannya.

\section{METODE PENELITIAN}

Penelitian ini dilaksanakan di SD Negeri 46 Rejang Lebong dengan subjek penelitian adalah guru kelas yang ada di sekolah dasar ini, baik yang sudah pegawai negeri sipil maupun yang masih wiyata bakti. Jumlah seluruh dewan guru yang menjadi subyek penelitian adalah adalah 14 orang. \Kondisi di SD Negeri 46 Rejang Lebong adalah Ketrampilan guru dalam menyusun perangkat pembelajaran masih rendah, makanya peneliti hendak Training perangkat pembelajaran Ketrampilan guru dalam menyusun perangkat pembelajaran dapat meningkat. Penelitian dilakukan pada tanggal Agustus 2019 sampai dengan November 2019, dalam tiga tahap yaitu tahap prasiklus, siklus I, dan siklu II yang dapat diuraikan sebagai berikut,

\section{Pra Siklus}

Perencanaan, Pada tahap ini peneliti belum mengadakan training perangkat pembelajaran. Peneliti melaksanakan observasi awal untuk mengetahui ketrampilan guru dalam menyusun perangkat pembelajaran. Pelaksanaan, Pada pelaksanaan pra siklus, peneliti melakukan observasi dan waancara terkait Ketrampilan guru dalam menyusun perangkat pembelajaran. Pengamatan, Pengamatan dilaksanakan melalui lembar observasi yang sudah di buat, peneliti tinggal mengisi format lembar observasi saja. Refleksi, refleksi merupakan kegiatan menganalisis semua data atau informasi yang dikumpulkan dari penelitian tindakan yang dilaksanakan, sehingga dapat diketahui berhasil atau tidaknya tindakan yang telah dilaksanakan dengan tujuan yang diharapkan.

\section{Siklus 1}

Pertama Perencanaan, pada tahap ini peneliti merumuskan dan mempersiapkan: rencana jadwal pelaksanaan tindakan, rencana pelaksanaan Training perangkat pembelajaran, membuat lembar observasi, dan mempersiapkan kelengkapan lain yang diperlukan dalam rangka analisis data. Kedua, pelaksanaan Training perangkat pembelajaran Siklus I dilaksanakan selama 3 hari. Pelaksanaan tindakan pada dasarnya disesuaikan dengan setting tindakan yang telah ditetapkan dalam rencana pelaksanaan. Ketiga Pengamatan, Setelah proses 
Training perangkat pembelajaran selesai maka dilakukan pengamatan terhadap ketrampilan guru dalam menyusun perangkat pembelajaran. Pengamatan dilakukan untuk mengetahui apakah training perangkat pembelajaran dapat meningkatkan Ketrampilan guru dalam menyusun perangkat pembelajaran. Keempat Refleksi, dilakukan untuk menganalisis semua data atau informasi yang dikumpulkan dari penelitian tindakan yang dilaksanakan, sehingga dapat diketahui berhasil atau tidaknya tindakan yang telah dilaksanakan dengan tujuan yang diharapkan.

\section{Siklus 2}

Pertama Perencanaan, pada tahap ini peneliti merumuskan dan mempersiapkan melakukan tindak lanjut siklus I, yaitu dalam siklus II dilakukan perbaikan. Peneliti yang dalam hal ini adalah kepala sekolah mencari kekurangan dan kelebihan training perangkat pembelajaran. Kelebihan yang ada pada siklus I dipertahankan pada siklus II, sedangkan kekurangannya diperbaiki. Peneliti menyiapkan lembar evaluasi (penilaian), lembar observasi untuk mengetahui apakah Training perangkat pembelajaran dapat meningkatkan Ketrampilan guru dalam menyusun perangkat pembelajaran. Kedua Tahap Pelaksanaan pada pelaksanaan Siklus II juga dilaksanakan 2 hari. Proses tindakan pada siklus II dengan melaksanakan Training perangkat pembelajaran berdasarkan pada pengalaman hasil dari siklus I. Dalam tahap ini peneliti melaksanakan metode yang diterapkan berdasarkan Tindakan pada siklus I, perbedaannya adalah pada siklus II lebih banyak praktek menyusun perangkat pembelajaran dari pada materi. Ketiga Pengamatan, Setelah proses Training perangkat pembelajaran selesai maka dilakukan pengamatan terhadap Ketrampilan guru dalam menyusun perangkat pembelajaran. Pengamatan dilakukan untuk mengetahui apakah Training perangkat pembelajaran dapat meningkatkan Ketrampilan guru dalam menyusun perangkat pembelajaran. Adapun yang di amati pada siklus 2 sama dengan yang diamati pada siklus 1. Keempat Refleksi, kegiatan ini dilakukan untuk menganalisis semua data atau informasi yang dikumpulkan dari penelitian tindakan yang dilaksanakan, sehingga dapat diketahui berhasil atau tidaknya tindakan yang telah dilaksanakan dengan tujuan yang diharapkan.

Agar pelaksanaan Training perangkat pembelajaran yang dilakukan dapat berjalan dengan baik, peneliti mengadakan pengamatan langsung terhadap ketrampilan guru dalam menyusun perangkat pembelajaran. Teknik pengumpulan data digunakan dalam penelitian ini adalah sebagai berikut: 1) Observasi yang digunakan untuk mengamati Ketrampilan guru dalam menyusun perangkat pembelajaran yang dilakukan pada saat Training perangkat pembelajaran berlangsung, dengan menggunakan instrumen lembar observasi; 2). Dokumentasi 
digunakan oleh peneliti karena dapat melengkapi dan menguatkan data-data yang sudah diperoleh mengenai Ketrampilan guru dalam menyusun perangkat pembelajaran. Dokumen ini berupa catatan harian, lembar observasi dan foto Training perangkat pembelajaran.

\section{HASIL PENELITIAN}

\section{Pra siklus}

Peneliti mengadakan beberapa persiapan yang diperlukan sebelum pelaksanaan penelitian. Adapun persiapan yang peneliti lakukan sebelum penelitian adalah sebagai berikut: a) melakukan observasi awal untuk mengidentifikasi masalah melalui wawancara dengan guru di SD Negeri 46 Rejang Lebong, b) melakukan observasi lanjutan untuk mencari informasi tentang ketrampilan guru dalam menyusun perangkat pembelajaran.

Pada pra siklus, peneliti belum mengadakan training perangkat pembelajaran karena pra siklus ini sebagai pembanding nantinya, bagaimana hasil ketrampilan guru dalam menyusun perangkat pembelajaran sebelum di adakan training perangkat pembelajaran dan sesudah di adakan training perangkat pembelajaran. Pada pra siklus, kepala sekolah atau peneliti meminta masingmasing guru membuat perangkat pembelajaran sesuai mapel yang di ampu. Peneliti mengecek hasil perangkat pembelajaran yang di buat oleh masing-masing guru tapi masih banyak guru yang belum mampu dan masih kesulitan menyusun perangkat pembelajaran. Berikut adalah hasil observasi pra siklus.

Tabel 1

Hasil Observasi Pra siklus

\begin{tabular}{|c|c|c|c|c|c|c|c|c|c|c|c|c|c|c|}
\hline \multirow[t]{2}{*}{ No } & \multirow[t]{2}{*}{ Nama Guru } & \multicolumn{3}{|c|}{$\begin{array}{c}\text { Indikator } \\
\mathrm{Ke} 1\end{array}$} & \multicolumn{3}{|c|}{$\begin{array}{l}\text { Indikator } \\
\text { Ke } 2\end{array}$} & \multicolumn{3}{|c|}{$\begin{array}{c}\text { Indikator } \\
\text { Ke } 3\end{array}$} & \multicolumn{3}{|c|}{$\begin{array}{c}\text { Indikator } \\
\text { Ke } 4\end{array}$} & \multirow[t]{2}{*}{$\begin{array}{l}\text { Total } \\
\text { Skor }\end{array}$} \\
\hline & & 3 & 2 & 1 & 3 & 2 & 1 & 3 & 2 & 1 & 3 & 2 & 1 & \\
\hline 1 & Kasminah, S.Pd & & & $\sqrt{ }$ & & & $\sqrt{ }$ & & $\sqrt{ }$ & & & & $\sqrt{ }$ & 5 \\
\hline 2 & Zulkifli, S.Pd & & & $\sqrt{ }$ & & & $\sqrt{ }$ & & & $\sqrt{ }$ & & & $\sqrt{ }$ & 4 \\
\hline 3 & Sri Kandung, S.Pd & & & $\sqrt{ }$ & & & $\sqrt{ }$ & & & $\sqrt{ }$ & & & $\sqrt{ }$ & 4 \\
\hline 4 & Hanafi, M.Pd & & & $\sqrt{ }$ & & & $\sqrt{ }$ & & & $\sqrt{ }$ & & & $\sqrt{ }$ & 4 \\
\hline 5 & Margono.S.Pd & & & $\sqrt{ }$ & & & $\sqrt{ }$ & & & $\sqrt{ }$ & & & $\sqrt{ }$ & 4 \\
\hline 6 & Kusmiadi, S.Pd & & & $\sqrt{ }$ & & & $\sqrt{ }$ & & & $\sqrt{ }$ & & & $\sqrt{ }$ & 4 \\
\hline 7 & Suwarno S.Pd & & & $\sqrt{ }$ & & & $\sqrt{ }$ & & & $\sqrt{ }$ & & & $\sqrt{ }$ & 4 \\
\hline 8 & Sudarwati, S.Pd & & & $\sqrt{ }$ & & & $\sqrt{ }$ & & & $\sqrt{ }$ & & & $\sqrt{ }$ & 4 \\
\hline 9 & Parjio & & & $\sqrt{ }$ & & & $\sqrt{ }$ & & & $\sqrt{ }$ & & & $\sqrt{ }$ & 4 \\
\hline 10 & Miyanto, S.Pd & & & $\sqrt{ }$ & & & $\sqrt{ }$ & & & $\sqrt{ }$ & & $\sqrt{ }$ & & \\
\hline 11 & Kaharudin Kamil, S.Pd & & & $\sqrt{ }$ & & & $\sqrt{ }$ & & & $\sqrt{ }$ & & & $\sqrt{ }$ & 4 \\
\hline 12 & Supriadi, S.Pd & & & $\sqrt{ }$ & & & $\sqrt{ }$ & & & $\sqrt{ }$ & & & $\sqrt{ }$ & 4 \\
\hline 13 & Anna Tamamah,S.Pd.I & & & $\sqrt{ }$ & & & $\sqrt{ }$ & & & $\sqrt{ }$ & & & $\sqrt{ }$ & 4 \\
\hline 14 & Marhadi, S.Pd.I & & & $\sqrt{ }$ & & & $\sqrt{ }$ & & & $\sqrt{ }$ & & & $\sqrt{ }$ & 4 \\
\hline
\end{tabular}


Keterangan:

Indikator Ke 1 : Guru menyusun silabus

Indikator Ke 2 : Guru menyusun PROTA

Indikator Ke 3 : Guru menyusun PROMES

Indikator Ke 4 : Guru menyusun RPP

Keterangan Skor:

3 : Sangat Benar

2: Cukup Benar

1: Kurang Benar

Skor maksimal tiap guru: 3X 4= 12

Skor maksimal semua guru 14 X $12=168$

Skor harapan $75 \%$ X 168=126

Kriteria penilaian:

112-168 = Ketrampilan guru dalam menyusun perangkat pembelajaran sudah sangat baik

56-111 = Ketrampilan guru dalam menyusun perangkat pembelajaran cukup baik

1-55 = Ketrampilan guru dalam menyusun perangkat pembelajaran kurang baik

Pada pra siklus ini di hasilkan skor 53, artinya ketrampilan guru dalam menyusun perangkat pembelajaran kurang baik, maka perlu di lanjutkan siklus I untuk lebih miningkatkan lagi ketrampilan guru dalam menyusun perangkat pembelajaran.

\section{Siklus I}

Persiapan

Pada tahap persiapan, peneliti mempersiapkan hal-hal berikut: a) Peneliti menyiapkan format perangkat pembelajaran yang sudah benar dan sesuai aturan K13; b) peneliti menyiapkan lembar observasi; c) Peneliti menyiapkan form yang nantinya di gunakan guru untuk latihan menyusun perangkat pembelajaran

\section{Pelaksanaan}

Dalam sebuah kegiatan sudah pasti terdapat waktu dan hari yang telah di tetapkan atau disepakati bersama dalam pelaksanaanya, begitu juga dengan training perangkat pembelajaran yang ada di SD Negeri 46 Rejang Lebong jadwal siklus I yaitu: training perangkat pembelajaran siklus I dilaksanakan selama 3 hari yakni tanggal 11, 12 dan 13 yang di lingkari merah adalah jadwal pelaksanaan 
Training perangkat pembelajaran yang ada di SD Negeri 46 Rejang Lebong. Adapun kegiatannya adalah sebagai berikut:

Pelaksanaan : Senin - Rabu ( 11,12 dan 13 September 2019)

Lokasi :SD Negeri 46 Rejang Lebong

Waktu : 07.30 s.d. selesai

Tabel 2

Hari : Senin, 11 September 2019

\begin{tabular}{llll}
\hline No & \multicolumn{1}{c}{ Waktu } & \multicolumn{1}{c}{ Acara } & Narasumber \\
\hline 1 & $07.30-08.00$ & Registrasi & Kepala Sekolah \\
\hline 2 & $08.00-08.30$ & Pembukaan & Trainer \\
\hline 3 & $08.30-10.00$ & $\begin{array}{l}\text { Materi seputar tentang perangkat } \\
\text { pembelajaran }\end{array}$ & Trainer \\
\hline 4 & $10.00-10.15$ & Istirahat & $\begin{array}{l}\text { Sistematika Penyusunan } \\
\text { perangkat pembelajaran }\end{array}$ \\
\hline 5 & $10.15-11.45$ & Ishoma & Trainer \\
\hline 6 & $11.45-12.45$ & $\begin{array}{l}\text { Praktek menyusun silabus dan } \\
\text { PROTA }\end{array}$ & Trainer dan guru \\
\hline 8 & $12.45-14.15$ & Penyimpulan Hari I &
\end{tabular}

Tabel 3

Hari Selasa,12 September 2019

\begin{tabular}{|c|c|c|c|}
\hline No & Waktu & Acara & $\begin{array}{c}\text { Nara } \\
\text { sumber }\end{array}$ \\
\hline 1 & $07.30-08.00$ & Registrasi & \\
\hline 2 & $08.00-08.30$ & Small Talk & Trainer \\
\hline 3 & $08.30-10.00$ & $\begin{array}{l}\text { Latihan menyusun perangkat pembelajaran dari silabus, } \\
\text { prota, promes dan RPP }\end{array}$ & Trainer \\
\hline 4 & $10.00-10.15$ & Istirahat & \\
\hline 5 & $10.15-11.45$ & $\begin{array}{l}\text { Pengecekan perangkat pembelajaran yang di susun oleh } \\
\text { masing-masing guru oleh nara sumber apa sudah benar } \\
\text { atau belum }\end{array}$ & Trainer \\
\hline 6 & $11.45-12.45$ & Ishoma & \\
\hline 7 & $12.45-14.15$ & $\begin{array}{l}\text { Setelah guru tahu kekurangan dan kelebihannya dimana } \\
\text { perangkat pembelajaran yang disusun maka guru } \\
\text { meembetulkan aspek-aspek yang salah yang tadi di } \\
\text { koreksi oleh nara sumber }\end{array}$ & Trainer \\
\hline 8 & 14.15 - selesai & Penutup & \\
\hline
\end{tabular}


Tabel 4

Hari Rabu,13 September 2019

\begin{tabular}{|c|c|c|c|}
\hline $\mathrm{No}$ & Waktu & Acara & Nara sumber \\
\hline 1 & $07.30-08.00$ & Registrasi & \\
\hline 2 & $08.00-08.30$ & Small Talk & \\
\hline 3 & $08.30-10.00$ & Menyusun perangkat pembelajaran & Trainer \\
\hline 4 & $10.00-10.15$ & Istirahat & \\
\hline 5 & $10.15-11.45$ & $\begin{array}{l}\text { Pengecekan perangkat pembelajaran } \\
\text { yang di susun oleh masing-masing guru oleh nara } \\
\text { sumber apa sudah benar atau belum }\end{array}$ & Trainer \\
\hline 6 & $11.45-12.45$ & Ishoma & \\
\hline 7 & $12.45-14.15$ & $\begin{array}{l}\text { Setelah guru tahu kekurangan dan kelebihannya dimana } \\
\text { perangkat pembelajaran } \\
\text { yang disusun maka guru meembetulkan aspek-aspek } \\
\text { yang salah yang tadi di koreksi oleh nara sumber }\end{array}$ & Trainer \\
\hline 8 & 14.15 - selesai & Penutup & \\
\hline
\end{tabular}

Observasi yang di lakukan peneliti adalah dengan menceklist lembar observasi yang telah di buat. Lembar observasinya adalah sebagai berikut:

Tabel 5

Lembar Observasi Siklus I

\begin{tabular}{|c|c|c|c|c|}
\hline NO & Indikator & $\begin{array}{l}\text { Sangat } \\
\text { Benar }\end{array}$ & $\begin{array}{l}\text { Cukup } \\
\text { Benar }\end{array}$ & $\begin{array}{c}\text { Kurang } \\
\text { Benar }\end{array}$ \\
\hline
\end{tabular}

1 Guru menyusun silabus

2 Guru menyusun PROTA

3 Guru menyusun PROMES 
Tabel 3

Hasil Observasi Siklus 1

\begin{tabular}{|c|c|c|c|c|c|c|c|c|c|c|c|c|c|c|}
\hline \multirow[t]{2}{*}{ No } & \multirow[t]{2}{*}{ Nama Guru } & \multicolumn{3}{|c|}{$\begin{array}{l}\text { Indikator } \\
\text { Ke } 1\end{array}$} & \multicolumn{3}{|c|}{$\begin{array}{l}\text { Indikator } \\
\operatorname{Ke} 2\end{array}$} & \multicolumn{3}{|c|}{$\begin{array}{l}\text { Indikator } \\
\text { Ke } 3\end{array}$} & \multicolumn{3}{|c|}{$\begin{array}{l}\text { Indikator } \\
\text { Ke } 4\end{array}$} & \multirow[t]{2}{*}{$\begin{array}{l}\text { Total } \\
\text { Skor }\end{array}$} \\
\hline & & 3 & 2 & 1 & 3 & 2 & 1 & 3 & 2 & 1 & 3 & 2 & 1 & \\
\hline 1 & Kasminah, S.Pd & & $\sqrt{ }$ & & & $\sqrt{ }$ & & & $\sqrt{ }$ & & & & $\sqrt{ }$ & 7 \\
\hline 2 & Zulkifli, S.Pd & $\sqrt{ }$ & & & $\sqrt{ }$ & & & & $\sqrt{ }$ & & $\sqrt{ }$ & & & 11 \\
\hline 3 & Sri Kandung, S.Pd & & $\sqrt{ }$ & & & $\sqrt{ }$ & & & $\sqrt{ }$ & & & $\sqrt{ }$ & & 8 \\
\hline 4 & Hanafi, M.Pd & & $\sqrt{ }$ & & & $\sqrt{ }$ & & & $\sqrt{ }$ & & & $\sqrt{ }$ & & 8 \\
\hline 5 & Margono.S.Pd & & $\sqrt{ }$ & & & $\sqrt{ }$ & & & $\sqrt{ }$ & & & & $\sqrt{ }$ & 7 \\
\hline 6 & Kusmiadi, S.Pd & & $\sqrt{ }$ & & & $\sqrt{ }$ & & & $\sqrt{ }$ & & & & $\sqrt{ }$ & 7 \\
\hline 7 & Suwarno S.Pd & & $\sqrt{ }$ & & & $\sqrt{ }$ & & & $\sqrt{ }$ & & & & $\sqrt{ }$ & 7 \\
\hline 8 & Sudarwati, S.Pd & & $\sqrt{ }$ & & & $\sqrt{ }$ & & & $\sqrt{ }$ & & & & $\sqrt{ }$ & 7 \\
\hline 9 & Parjio & & $\sqrt{ }$ & & & $\sqrt{ }$ & & & $\sqrt{ }$ & & & $\sqrt{ }$ & & 8 \\
\hline 10 & Miyanto, S.Pd & & $\sqrt{ }$ & & & $\sqrt{ }$ & & & $\sqrt{ }$ & & & $\sqrt{ }$ & & 8 \\
\hline 11 & Kaharudin Kamil, S.Pd & & $\sqrt{ }$ & & & $\sqrt{ }$ & & & $\sqrt{ }$ & & & & $\sqrt{ }$ & 7 \\
\hline 12 & Supriadi, S.Pd & & $\sqrt{ }$ & & & $\sqrt{ }$ & & & $\sqrt{ }$ & & & & $\sqrt{ }$ & 7 \\
\hline 13 & Anna Tamamah,S.Pd.I & & $\sqrt{ }$ & & & $\sqrt{ }$ & & & $\sqrt{ }$ & & & & $\sqrt{ }$ & 7 \\
\hline 14 & Marhadi, S.Pd.I & & $\sqrt{ }$ & & & $\sqrt{ }$ & & & $\sqrt{ }$ & & & & $\sqrt{ }$ & 7 \\
\hline \multicolumn{2}{|c|}{ Skor total } & & & & & & & & & & & & & 106 \\
\hline
\end{tabular}

Keterangan:

Indikator Ke 1 : Guru menyusun silabus

Indikator Ke 2 : Guru menyusun PROTA

Indikator Ke 3 : Guru menyusun PROMES

Indikator Ke 4 : Guru menyusun RPP

Keterangan Skor:

3 : Sangat Benar

2: Cukup Benar

1: Kurang Benar

Skor maksimal tiap guru: $3 \mathrm{X} 4=12$

Skor maksimal semua guru 14 X $12=168$

Skor harapan $75 \%$ X 168= 126

Kriteria penilaian:

112-168 = Ketrampilan guru dalam menyusun perangkat pembelajaran sudah sangat baik

56-111 = Ketrampilan guru dalam menyusun perangkat pembelajaran cukup baik

1-55 = Ketrampilan guru dalam menyusun perangkat pembelajaran kurang baik 
Pada siklus I ini di hasilkan skor 106, artinya ketrampilan guru dalam menyusun perangkat pembelajaran cukup baik, maka perlu di lanjutkan siklus II untuk lebih miningkatkan lagi ketrampilan guru dalam menyusun perangkat pembelajaran.

\section{Refleksi}

Pada siklus I ini, guru sudah mulai faham dan mampu menyusun perangkat pembelajaran walaupun belum maksimal karena skor yang di dapat dari hasil observasi adalah 106 dengan kriteria skor 168 kriteria minimal adalah 75\% adalah 126, yang berarti ketrampilan guru dalam menyusun perangkat pembelajaran cukup baik. Pada siklus I ini, guru sudah mampu perangkat pembelajaran menyusun silabus, menyusun PROTA, menyusun PROMES dan guru sudah mampu menyusun RPP.

\section{Siklus II}

Persiapan

Pada tahap persiapan, peneliti mempersiapkan hal-hal berikut: a) peneliti menyiapkan format perangkat pembelajaran yang sudah benar dan sesuai aturan $\mathrm{K} 13$, b) peneliti menyiapkan lembar observasi, c) peneliti menyiapkan form yang nantinya di gunakan guru untuk latihan menyusun perangkat pembelajaran

\section{Pelaksanaan}

Dalam sebuah kegiatan sudah pasti terdapat waktu dan hari yang telah di tetapkan atau disepakati bersama dalam pelaksanaanya, begitu juga dengan training perangkat pembelajaran yang ada di SD Negeri 46 Rejang Lebong jadwal siklus II yaitu di laksanakan selama 2 hari

Tabel 7

Lembar Observasi Siklus II

\begin{tabular}{llccc}
\hline NO & \multicolumn{1}{c}{ Indikator } & $\begin{array}{c}\text { Sangat } \\
\text { Benar }\end{array}$ & $\begin{array}{c}\text { Cukup } \\
\text { Benar }\end{array}$ & $\begin{array}{c}\text { Kurang } \\
\text { Benar }\end{array}$ \\
\hline 1 & Guru menyusun silabus & & & \\
\hline 2 & Guru menyusun PROTA & & \\
\hline 3 & Guru menyusun PROMES & & \\
\hline 4 & Guru menyusun RPP & \\
\hline
\end{tabular}


Tabel 8

Hasil Observasi siklus II

\begin{tabular}{|c|c|c|c|c|c|c|c|c|c|c|c|c|c|c|}
\hline \multirow[t]{2}{*}{ No } & \multirow[t]{2}{*}{ Nama Guru } & \multicolumn{3}{|c|}{$\begin{array}{l}\text { Indikator } \\
\text { Ke } 1\end{array}$} & \multicolumn{3}{|c|}{$\begin{array}{l}\text { Indikator } \\
\text { Ke } 2\end{array}$} & \multicolumn{3}{|c|}{$\begin{array}{c}\text { Indikator } \\
\text { Ke } 3\end{array}$} & \multicolumn{3}{|c|}{$\begin{array}{c}\text { Indikator } \\
\operatorname{Ke} 4\end{array}$} & \multirow[t]{2}{*}{$\begin{array}{l}\text { Total } \\
\text { Skor }\end{array}$} \\
\hline & & 3 & 2 & 1 & 3 & 2 & 1 & 3 & 2 & 1 & 3 & 2 & 1 & \\
\hline 1 & Kasminah, S.Pd & $\sqrt{ }$ & & & $\sqrt{ }$ & & & & $\sqrt{ }$ & & $\sqrt{ }$ & & & 11 \\
\hline 2 & Zulkifli, S.Pd & $\sqrt{ }$ & & & $\sqrt{ }$ & & & $\sqrt{ }$ & & & $\sqrt{ }$ & & & 12 \\
\hline 3 & Sri Kandung, S.Pd & $\sqrt{ }$ & & & $\sqrt{ }$ & & & $\sqrt{ }$ & & & $\sqrt{ }$ & & & 12 \\
\hline 4 & Hanafi, M.Pd & $\sqrt{ }$ & & & $\sqrt{ }$ & & & & $\sqrt{ }$ & & $\sqrt{ }$ & & & 11 \\
\hline 5 & Margono.S.Pd & $\sqrt{ }$ & & & $\sqrt{ }$ & & & $\sqrt{ }$ & & & $\sqrt{ }$ & & & 12 \\
\hline 6 & Kusmiadi, S.Pd & $\sqrt{ }$ & & & $\sqrt{ }$ & & & $\sqrt{ }$ & & & $\sqrt{ }$ & & & 12 \\
\hline 7 & Suwarno S.Pd & $\sqrt{ }$ & & & $\sqrt{ }$ & & & & $\sqrt{ }$ & & $\sqrt{ }$ & & & 11 \\
\hline 8 & Sudarwati, S.Pd & $\sqrt{ }$ & & & $\sqrt{ }$ & & & $\sqrt{ }$ & & & $\sqrt{1}$ & & & 12 \\
\hline 9 & Parjio & $\sqrt{ }$ & & & $\sqrt{ }$ & & & $\sqrt{ }$ & & & $\sqrt{ }$ & & & 12 \\
\hline 10 & Miyanto, S.Pd & $\sqrt{ }$ & & & $\sqrt{ }$ & & & & $\sqrt{ }$ & & $\sqrt{ }$ & & & 11 \\
\hline 11 & Kaharudin K, S.Pd & $\sqrt{ }$ & & & $\sqrt{ }$ & & & $\sqrt{ }$ & & & $\sqrt{ }$ & & & 12 \\
\hline 12 & Supriadi, S.Pd & $\sqrt{ }$ & & & $\sqrt{ }$ & & & $\sqrt{ }$ & & & $\sqrt{ }$ & & & 12 \\
\hline 13 & Anna Tamamah,S.Pd.I & $\sqrt{ }$ & & & $\sqrt{ }$ & & & & $\sqrt{ }$ & & $\sqrt{ }$ & & & 11 \\
\hline 14 & Marhadi, S.Pd.I & $\sqrt{ }$ & & & $\sqrt{ }$ & & & $\sqrt{ }$ & & & $\sqrt{ }$ & & & 12 \\
\hline \multicolumn{2}{|c|}{ Skor total } & & & & & & & & & & & & & 163 \\
\hline
\end{tabular}

Keterangan:

Indikator Ke 1 : Guru menyusun silabus

Indikator Ke 2 : Guru menyusun PROTA

Indikator Ke 3 : Guru menyusun PROMES

Indikator Ke 4 : Guru menyusun RPP

Keterangan Skor:

3 : Sangat Benar

2: Cukup Benar

1: Kurang Benar

Skor maksimal tiap guru: $3 \mathrm{X} 4=12$

Skor maksimal semua guru 14 X $12=168$

Skor harapan $75 \%$ X 168=126

Kriteria penilaian:

112-168 = Ketrampilan guru dalam menyusun perangkat pembelajaran sudah sangat baik

56-111 = Ketrampilan guru dalam menyusun perangkat pembelajaran cukup baik

1-55 = Ketrampilan guru dalam menyusun perangkat pembelajaran kurang baik 
Refleksi

Pada siklus II ini, guru sudah mulai faham dan mampu menyusun perangkat pembelajaran dan sudah maksimal karena skor yang di dapat dari hasil observasi adalah 163 dengan kriteria Skor maksimal 168 kriteria minimal 75\% adalah 126, yang berarti ketrampilan guru dalam menyusun perangkat pembelajaran sudah sangat baik. Pada siklus II ini, guru sudah mampu menyusun silabus, menyusun PROTA, menyusun PROMES dan guru sudah mampu menyusun RPP dengan baik.

\section{PEMBAHASAN}

Pada pra siklus ini di hasilkan skor 53, artinya ketrampilan guru dalam menyusun Perangkat Pembelajaran kurang baik, maka perlu di lanjutkan siklus I untuk lebih miningkatkan lagi ketrampilan guru dalam menyusun perangkat pembelajaran.

Pada siklus I, guru sudah mulai faham dan mampu menyusun perangkat pembelajaran walaupun belum maksimal karena skor yang di dapat dari hasil observasi adalah 106 dengan kriteria skor maksimal tiap guru: 3X 4= 12 Skor maksimal semua guru 14 X 12=168 Skor harapan $75 \%$ X 168=126 yang berarti ketrampilan guru dalam menyusun perangkat pembelajaran cukup baik.
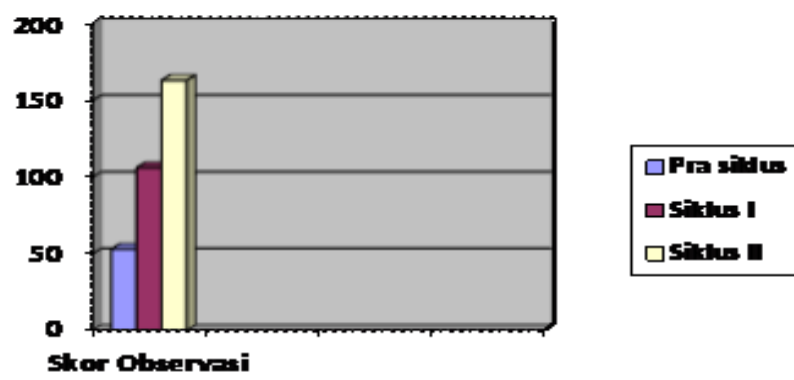

Gambar 1

Grafik Peningkatan Ketrampilan guru dalam Menyusun Perangkat Pembelajaran dari pra siklus, siklus I ke siklus II

\section{SIMPULAN}

Setelah melakukan training perangkat pembalajaran guru disimpulkan ketrampilan guru dalam menyusun perangkat pembelajaran mengalami peningkatan pada proses pentrainingan. Pada siklus I dan II dalam menyusun silabus, program tahunan, program semester, dan Rencana Pelaksanaan Pembelajaran (RPP) sudah sangat baik. 


\section{DAFTAR PUSTAKA}

Anonim. (1999). Penelitian Tindakan Kelas. Jakarta : Departemen Pendidikan dan Kebudayaan.

Anonim. (2007). Pedoman Bantuan Langsung (Block Grant) Pelaksanaan Penelitian Tindakan Bagi Pengawas Sekolah SMA/SMK. Jakarta : Direktorat Tenaga Kependidikan Direktorat Jendral Peningkatan Mutu Pendidikan Dasar dan Menengah Direktorat Tenaga Kependidikan. Anonim, 2005. Undang-Undang Republik Indonesia Tentang Guru dan Dosen. Jakarta : Cemerlang.

Anonim. (2008). Petunjuk Teknis Penelitian Tindakan sekolah (School Action Research) Peningkatan Kompetensi Supervisi Pengawas Sekolah SMA/SMK. Jakarta : Departemen Pendidikan Nasional Direktorat Jendral PMPTS. Arikanto S dan S. Supardi, 2006, Penelitian Tindakan Kelas. Jakarta : Bumi Aksara.

Basuki,W. (2003). Penelitian Tindakan Kelas. Jakarta : Departemen Pendidikan Nasional Direktorat Pendidikan Dasar dan Menengah Direktorat Tenaga Kependidikan. Departemen Pendidikan Nasional, 2003. Undang Undang Republik Indonesia Nomor 20 Tahun 2003 Tentang Sistem Pendidikan Nasional. Biro Hukum dan Organisasi Sekretariat Jendral Departemen Pendidikan Nasional.

Siswoyo, (2013). Kumpulan Materi Perbekalan Profesi Bagi Jabatan Fungsional Pengawas Sekolah dan Kepala Sekolah, Dalam Penulisan Karya Tulis Ilmiah. Direktorat Jendral Peningkatan Mutu Pendidikan dan Tenaga Pendidikan, Direktorat Tenaga Kependidikan. 